\title{
Mechanisms of Up-Valley Winds
}

\author{
GABRIELE RAMPANELli AND DinO ZARDI \\ Dipartimento di Ingegneria Civile ed Ambientale, Università degli studi di Trento, Trento, Italy \\ RICHARD ROTUNNO \\ National Center for Atmospheric Research,* Boulder, Colorado
}

(Manuscript received 27 March 2003, in final form 9 July 2004)

\begin{abstract}
The basic physical mechanisms governing the daytime evolution of up-valley winds in mountain valleys are investigated using a series of numerical simulations of thermally driven flow over idealized three-dimensional topography. The three-dimensional topography used in this study is composed of two, two-dimensional topographies: one a slope connecting a plain with a plateau and the other a valley with a horizontal floor. The present two-dimensional simulations of the valley flow agree with results of previous investigations in that the heated sidewalls produce upslope flows that require a compensating subsidence in the valley core bringing down potentially warmer air from the stable free atmosphere. In the context of the three-dimensional valley-plain simulations, the authors find that this subsidence heating in the valley core is the main contributor to the valleyplain temperature contrast, which, under the hydrostatic approximation, is the main contributor to the valleyplain pressure difference that drives the up-valley wind.
\end{abstract}

\section{Introduction}

Thermally driven wind in mountain valleys has been the subject of many observations and theoretical investigations. Insolation of valley areas during the day induces heating of air layers close to the ground and thermally driven upslope flows; likewise, radiative cooling of valley areas during the night produces downslope flows. When a valley has little variation in width along its axis, the cross-valley circulation induced by the "slope flow" can be considered essentially two-dimensional in the cross-valley plane. However, when there is a strong variation of valley width with distance along the valley axis, a three-dimensional circulation, known as the "valley wind," is induced. Using a combination of idealized numerical simulations and analysis we reconsider here the basic mechanisms responsible for the valley wind.

Pioneering work by early Austrian and German meteorologists provided the basic observational results and concepts regarding the valley wind. These contributions

\footnotetext{
* The National Center for Atmospheric Research is sponsored by the National Science Foundation.

Corresponding author address: Dr. Dino Zardi, Dipartimento di Ingegneria Civile ed Ambientale, Università degli studi di Trento, via Mesiano 77, I-38050 Trento, Italy.

E-mail: Dino.Zardi@ing.unitn.it
}

were clearly summarized and brought to a unified and consistent theory in the extensive and thorough review by Wagner (1938). The understanding based on this early work is summarized in the well-known schematic diagram of Defant (1949, reproduced in Fig. 1), which shows the basic features of slope and valley winds produced in a typical diurnal cycle. More recent reviews on the subject have been provided by Whiteman (1990) concerning observations of the valley wind and by Egger (1990) concerning modeling and theory. According to Fig. 1, the basic requirement for producing a valley wind is for the valley to widen to a degree where it can be considered a plain. Various field measurements (e.g., Nickus and Vergeiner 1984; Vergeiner and Dreiseitl 1987) have shown that there are larger daily temperature ranges within a valley than there are in the adjacent plain at any height within the valley. The associated variation of hydrostatic pressure between the valley and the plain provides the basic force that produces the valley wind. Hence knowledge of the factors responsible for the enhanced temperature variation of the valley atmosphere occupies a central role in the theory of valley winds. Wagner (1932) suggested that the key factor is the smaller amount of air within the valley volume (i.e., the volume defined by the valley topped by a horizontal surface at the ridge top) than that within a volume of the same height over the adjacent plain. As a result, the same solar radiation flux through the equal areas topping the valley and the plain, respectively, re- 

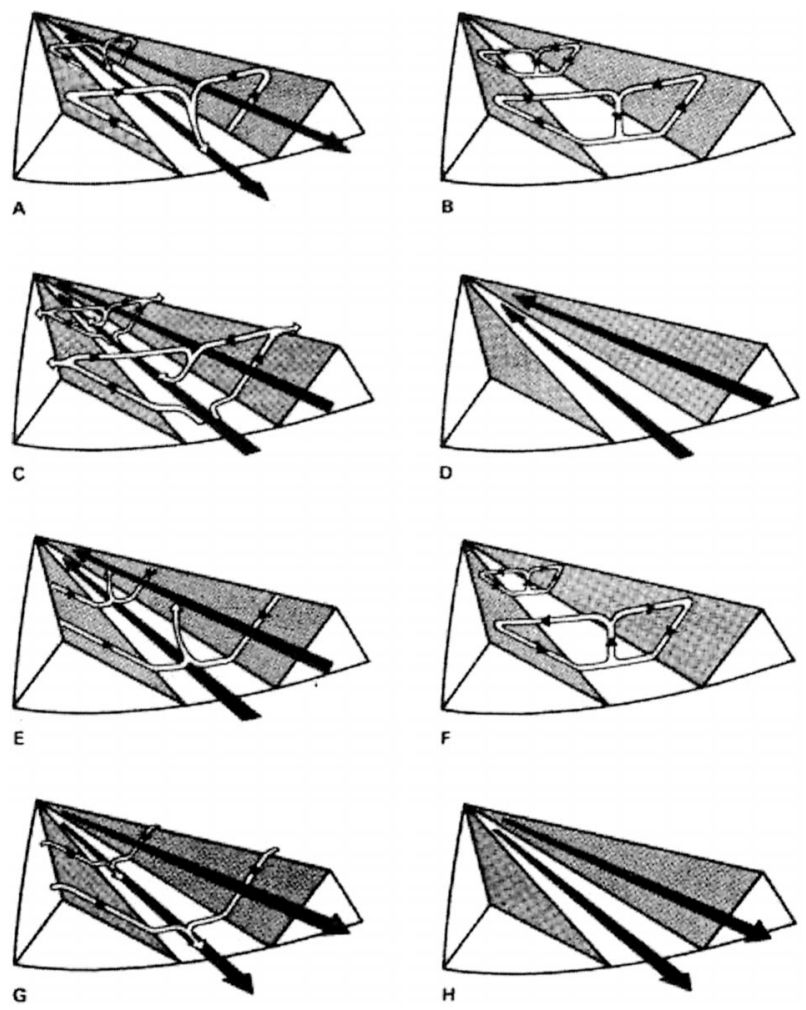

FIG. 1. Diurnal cycle of valley winds (after Defant 1949, 1951). (a) Sunrise: onset of upslope winds (white arrows); continuation of mountain wind (black arrows). Valley is cold, plains are warm. (b) Forenoon (about 0900): strong slope winds, transition from mountain wind to valley wind. Valley temperature is same as plain. (c) Noon and early afternoon: diminishing slope winds; fully developed valley wind. Valley is warmer than plains. (d) Late afternoon: slope winds have ceased, valley wind continues. Valley is still warmer than plain. (e) Evening: onset of downslope winds, diminishing valley wind. Valley is slightly warmer than plains. (f) Early night: well developed downslope winds, transition from valley wind to mountain wind. Valley and plains are at same temperature. (g) Middle of the night: downslope winds continue, mountain wind fully developed. Valley is colder than plains. (h) Late night to morning: downslope winds have ceased, mountain wind fills valley. Valley is colder than plain.

sults in stronger warming of the smaller valley air volume. Under the above-stated assumptions, one can derive a formula in which the ratio of volume-averaged valley to plain temperature (called the topographic amplification factor) is proportional to the ratio of plain to valley volume (Whiteman 1990, 9-12; Vergeiner 1982; Neininger 1982; Steinacker 1984).

In the present work we report on numerical simulations of the thermally driven flow produced using idealized valley-plain topographies in the spirit of that depicted in Fig. 1. Consistent with the early studies, the simulations indicate that there is a strong difference in temperature between the valley air and that of the adjacent plain. Analysis of the valley-plain simulations indicates the important role of the cross-valley circulation in elevating central-valley temperatures during the day, as found in purely two-dimensional (valley only) calculations (e.g., Kondo et al. 1989; Egger 1990; Noppel and Fiedler 2002). Our analysis further shows that the drop in hydrostatic pressure associated with the subsidence warming in the valley drives the valley wind from the plain (where there is no valley circulation and, hence, no subsidence warming).

The foregoing explanation, based on the cross-valley circulation, is naturally outside the reach of the volume effect theory, which does not require detailed knowledge of the interior valley flow other than that it must not transport heat through the valley top. To the authors' knowledge, there has not yet been a quantitative evaluation (from either observations or numerical simulations) of the extent to which the latter condition holds. The present simulations afford us the opportunity to make such an evaluation. Analysis of the present simulations suggests that the heat fluxes associated with the above-described cross-valley circulations reach well beyond the valley top and that the temperature excess in the valley center is mostly a consequence of subsidence warming associated with the cross-valley circulation.

\section{Modeling of valley winds}

To investigate the factors that produce the thermally driven wind from a plain to a valley (Figs. 1b-d), we performed numerical simulations based on an idealized version of a typical valley-plain system shown in Fig. 2 , which is similar to the one used in McNider and Pielke (1981, their Fig. 9) and, more recently, by Li and Atkinson (1999, their Fig. 1c). The topography and computational domain shown in Fig. 2 were chosen to satisfy the following criteria. First and foremost is the criterion that the bottom of the valley has the same elevation as that of the adjacent plain so that there could be no contribution to the valley flow from an upslope wind. The second criterion is that the valley-plain domain be long enough to contain completely the alongvalley wind system so that there could be no question about the possibly uncertain effects of numerical boundary conditions in the along-valley direction. Third, the valley slopes, while realistically steep, are not so steep as to cause numerical inaccuracy in the flow represented by the terrain-following grid system used in the numerical simulations.

The analytical expression for the topography used in this study satisfying these criteria is given by

$$
z=h(x, y)=h_{P} h_{Y}(y) h_{X}(x),
$$

where

$h_{Y}(y)=\frac{1}{2}+\frac{1}{2} \tanh \left(\frac{y}{S_{y}}\right)$ and 


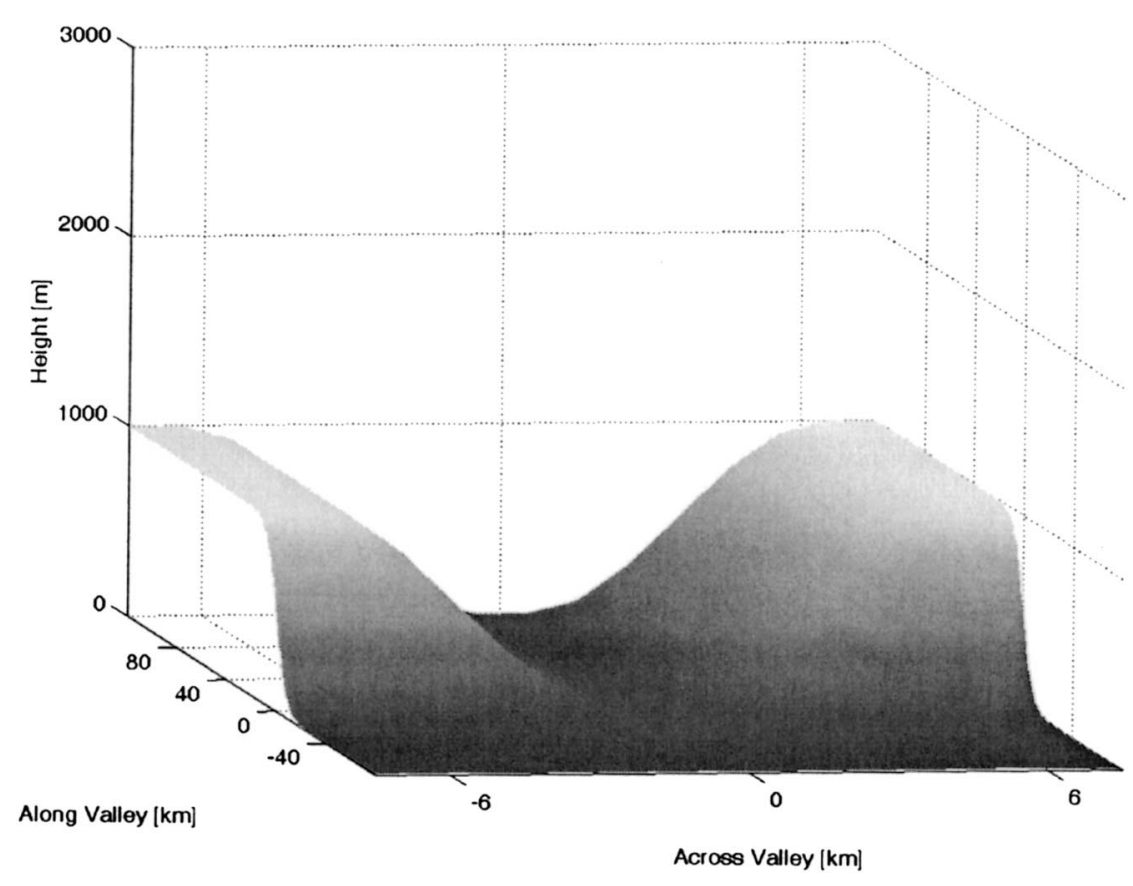

FIG. 2. View of the three-dimensional idealized valley-plain topography and domain adopted in this paper.

$h_{X}(x)= \begin{cases}1, & |x|>S_{x}+V_{x} \\ \frac{1}{2}-\frac{1}{2} \cos \left(\pi \frac{|x|-V_{x}}{S_{x}}\right), & V_{x}<|x|<S_{x}+V_{x} \\ 0, & |x|<V_{x} .\end{cases}$

Notice that the topography $h(x, y)$ is the product of two simpler ones: a slope connecting two plateaus $h_{Y}(y)$ and an infinitely long valley $h_{X}(x)$; each will be considered individually in section 3 .

We present here simulations of winds occurring in a valley of medium size with $S_{x}=6 \mathrm{~km}$ (sloping sidewall width) and $V_{x}=0.5 \mathrm{~km}$ (valley floor half width), resulting in a crest-to-crest width between ridge top heights at the valley sidewalls $2\left(S_{x}+V_{x}\right)=13 \mathrm{~km}$. Beyond the ridge tops there are plateaus extending 1 $\mathrm{km}$ to the edges of the computational domain located at $x= \pm 7.5 \mathrm{~km}$. In the along-valley, or $y$ direction, we take $S_{y}=8 \mathrm{~km}$ and let $y=0$ define the "mouth" of the valley [i.e., $h_{Y}(0)=1 / 2$ ]; the computational domain extends from $y=-80$ to $120 \mathrm{~km}$. Conditions at both $x$ and $y$ boundaries are discussed below. For all simulations the valley depth $h_{P}=1 \mathrm{~km}$. Maximum values for the slopes can be calculated from (2) and (3), yielding $0.5 h_{P} / S_{y}=0.0625$ for the plateau and $0.5 \pi h_{P} / S_{x}=$ 0.2618 for the valley.

To simulate thermally forced winds, the Weather Research and Forecasting (WRF) model has been adopted (Michalakes et al. 2000). The WRF model is a generalpurpose model that can be used for operational numerical weather prediction as well as for research. Here we describe a research application of WRF to the study of the valley wind. For simplicity of interpretation we will view the flow in Cartesian coordinates and neglect the Coriolis effect. With these restrictions, the WRF model can be configured to solve the following equations.

Equation of state:

$$
p=\rho R_{d} T
$$

Conservation of mass:

$$
\frac{\partial \rho}{\partial t}+\frac{\partial U}{\partial x}+\frac{\partial V}{\partial y}+\frac{\partial W}{\partial z}=0
$$

Conservation of momentum:

$$
\begin{aligned}
& \frac{\partial U}{\partial t}+c_{p} \Theta \frac{\partial \pi}{\partial x}=-\frac{\partial U u}{\partial x}-\frac{\partial V u}{\partial y}-\frac{\partial W u}{\partial z}+F_{x}, \\
& \frac{\partial V}{\partial t}+c_{p} \Theta \frac{\partial \pi}{\partial y}=-\frac{\partial U v}{\partial x}-\frac{\partial V v}{\partial y}-\frac{\partial W v}{\partial z}+F_{y},
\end{aligned}
$$

and

$\frac{\partial W}{\partial t}+c_{p} \Theta \frac{\partial \pi}{\partial z}+g \rho=-\frac{\partial U w}{\partial x}-\frac{\partial V w}{\partial y}-\frac{\partial W w}{\partial z}+F_{z} ;$

and

Conservation of energy:

$$
\frac{\partial \Theta}{\partial t}+\frac{\partial U \theta}{\partial x}+\frac{\partial V \theta}{\partial y}+\frac{\partial W \theta}{\partial z}=\rho Q
$$

In the above set of equations,

$$
U=\rho u, \quad V=\rho v, \quad W=\rho w, \quad \Theta=\rho \theta,
$$


where $(u, v, w)$ are the velocity components in the (x, $y, z)$ directions, $\theta$ is the potential temperature, and $\rho$ is the air density. The other variables appearing above are the absolute temperature $T$ and the Exner function $\pi=$ $\left(p / p_{0}\right)^{R_{d} / c_{p}}$, where $p$ is the pressure and $p_{0}=1000 \mathrm{hPa}$ is a reference value. The specific heat at constant pressure for dry air is given by $c_{p}=1004.5 \mathrm{~J} \mathrm{~K}^{-1} \mathrm{~kg}^{-1}$, and $R_{d}=(2 / 7) c_{p}$ is the gas constant for dry air; $F_{x}, F_{y}$, and $F_{z}$ are friction terms.

In order to satisfy the fundamental boundary condition of no flow through the topography, the model uses terrain-following coordinates as described in Michalakes et al. (2000).

The computational domain of the simulations is 200 $\mathrm{km}$ in the $y$ (along valley) direction and $15 \mathrm{~km}$ in the $x$ (across valley) direction and is covered by a rectangular grid of $200 \times 15$ equally spaced points $(\Delta y=$ $\Delta x=1 \mathrm{~km}$ ). The computational domain extends to 5 $\mathrm{km}$ in the vertical direction and is covered by 100 equally spaced grid points, starting from the ground (thus $\Delta z$ $=40 \mathrm{~m}$ over the plateau and $\Delta z=50 \mathrm{~m}$ over the valley floor). The time step adopted is $12 \mathrm{~s}$ for the advection terms with a 1.2-s time step to compute the acoustic modes. A third-order-accurate Runge-Kutta scheme is used for the time integration, and third- and fifth-orderaccurate spatial discretization schemes are used for the vertical and horizontal advection schemes, respectively (Wicker and Skamarock 2002).

A reasonable compromise between realism and simplicity leads to the following choices for the boundary conditions: as mentioned, the terrain-following coordinate is specifically designed to enforce the impermeability condition at the lower coordinate surface; in addition we let the stress be zero there simply to minimize the number of effects that may modify, but cannot produce, the valley wind. At the upper domain boundary, a rigid lid $(w=0)$ is employed since we have found that there is little or no vertically propagating gravity waves produced in the present simulations. At the northern and southern ends of the valley-plain system $(y=$ -80 and $+120 \mathrm{~km}$, respectively), we place vertical impermeable walls; since the heating cycle lasts only a finite time $(6 \mathrm{~h})$, the along-valley circulation has only a finite extent, and we have found through trial and error that the solution features of interest here are not sensitive to these walls as long they are located roughly $80 \mathrm{~km}$ or more from the valley mouth. Finally, the choice of boundary condition in the $x$ directions presents two interesting possibilities: periodic conditions would mean that simulations pertain to an infinite series of repeating hills and valleys. However, our intention here is to study the valley in isolation from other valleys and hence we choose "open" boundary conditions (at $x= \pm 7.5 \mathrm{~km}$ ), which allow disturbances to pass through them with minimal reflection and ideally should produce the solution for an infinite domain. (For the open boundary condition, the fifth-order advection scheme used here goes to third order at the third point from the boundary and second order at the second point.)

The present study is concerned with the fundamental causes of the valley wind and, accordingly, we choose to study the evolution of a motionless $(u=v=w=$ 0 ), stably stratified atmosphere (a hypothetical morning condition) defined by

$$
\theta=\theta_{00}+\Gamma z
$$

where $\Gamma=3.2 \mathrm{~K} \mathrm{~km}^{-1}$ and $\theta_{00}=300 \mathrm{~K}$. To produce motion from a state of rest, a simple heating is applied along $z=h(x, y)$ specified by

$$
Q=Q_{\max } \sin (\omega t)
$$

where $\omega=2 \pi /(24 \mathrm{~h}), Q_{\max }=200 \mathrm{~W} \mathrm{~m}^{-2}$, and the model is integrated forward for one-quarter of a diurnal cycle. Again, in the interest of arriving at the clearest explanation for the valley wind, effects such as varying sun angle, shading, etc., have been neglected.

The first thing that happens when a realistically large heating is applied to the ground surface is that a superadiabatic layer forms. Since the resolution used here $(\Delta x=\Delta y=1 \mathrm{~km}$ and $100 \mathrm{z}$ levels up to $H=5000$ $\mathrm{m})$ is far too coarse to simulate directly the ensuing turbulent motions, recourse must be made to a parameterization. Hence the philosophy of this model and others of its type (e.g., McNider and Pielke 1981) is that the domain and resolution are chosen to resolve the flow features that are on the scale of the topography, but the effects of vertical turbulent heat transfer must be somehow represented. Therefore, a fundamental building block for understanding the valley wind is a knowledge of the behavior of the convective boundary layer.

In keeping with the philosophy of the present work of using simple but realistic models, we use the scheme developed by Troen and Mahrt (1986, hereafter referred to as TM) in the WRF model to represent the effects of convective heat transfer in the vertical direction. There is a wealth of knowledge on the simple case of the growth of the mixed layer under light wind conditions over flat horizontally homogeneous terrain (see, e.g., Stull 1988), and the simple TM model provides an excellent first approximation to the behavior of the convective boundary layer. Figure 3 shows the solution for potential temperature $\theta(=T \pi)$ from the WRF model simulating the case of an atmosphere over flat, uniform terrain using the TM boundary model and heating specified as in (12). As explained in TM, the basic features of the convective boundary layer are captured by the parameterization, such as a vertical heat flux profile that is a nearly linear function of height and, consequently, a vertical profile of $\theta$ that is nearly constant ("well mixed") in a boundary layer capped by an inversion at the top.

Although the profiles shown in Fig. 3 are realistic representations of the convective boundary layer, the shallow superadiabatic layer produced near the ground is an unstable situation as far as a mesoscale model is 


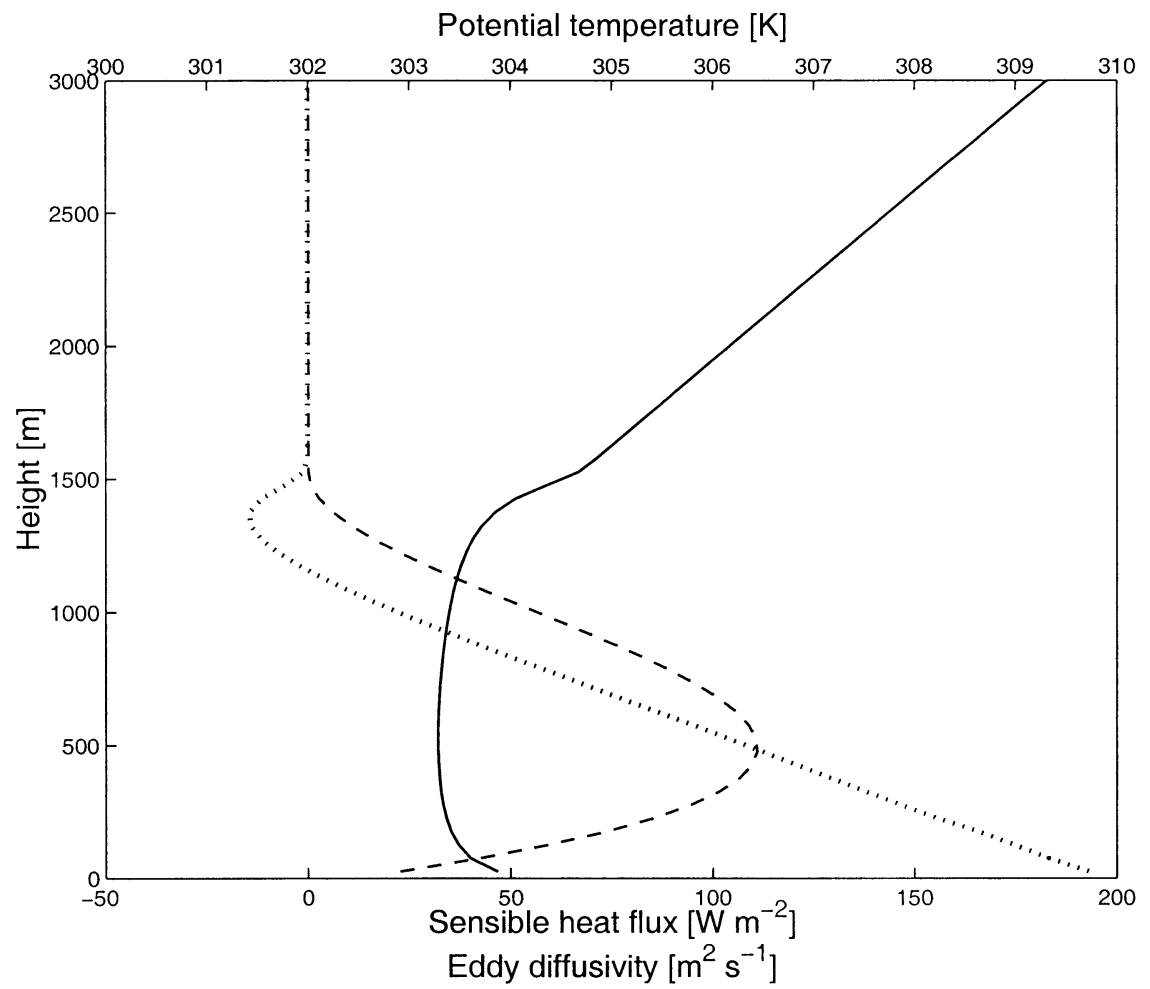

FIG. 3. Profiles of potential temperature $\theta$ (solid line), eddy diffusivity $K_{m}$ (dashed line), and turbulent heat flux, $-K_{m}(\partial \theta / \partial z-\gamma)$ (dotted line) in a convective boundary layer $6 \mathrm{~h}$ after "sunrise."

concerned. With the resolution used here $(\Delta x=\Delta y=$ $1 \mathrm{~km})$, we found that shallow convective circulations appeared in the superadiabatic layer at the minimum resolved scale $(4 \Delta x)$. At the coarser horizontal resolutions typical of mesoscale models, such circulations would grow too slowly to be noticed. Hence the present simulations are in a resolution regime where turbulence cannot be explicitly resolved, yet the superadiabatic layer can induce circulations that grow to noticeable size over the integration period. Recognizing the circulations as an inadequacy of the parameterization, we decided to eliminate them by adding to the rhs of (6)-(9) the second-order quasi-horizontal filter, $\rho K_{H} \nabla_{H}^{2} \chi$, where $\chi=u, v, w, \theta$, respectively; $\nabla_{H}^{2}=\partial^{2} / \partial x^{2}+\partial^{2} / \partial y^{2}$, where the derivatives are taken along the model terrainfollowing coordinate, and $K_{H}=300 \mathrm{~m}^{2} \mathrm{~s}^{-1}$. The effects of the filter on the features of interest here will be evaluated in section 5 .

\section{Two-dimensional circulations}

Before proceeding to the discussion of the simulations of thermally driven flow over the three-dimensional topography $z=h(x, y)$ (Fig. 2), it will be useful to examine and review first the solutions produced in the two twodimensional topographies, $z=h_{Y}(y)$ (the plateau) and $z=h_{X}(x)$ (the valley), that constitute the three-dimensional valley-plain topography.

\section{a. Thermally driven wind along a slope connecting two plateaus}

Exact solutions for thermally driven flow in a nonrotating, stably stratified fluid over an infinite plane of constant slope were given by Prandtl (1942). Assuming constant viscosity and thermal conductivity and a fixed thermal anomaly at the surface, Prandtl's solution illustrates that a steady-state flow can be established in which heat conducted away from the slope is exactly balanced by an upslope advection of cooler air. Prandtl's analytical solution for along-slope velocity is of the form

$$
u(n) \approx \exp (-n / l) \sin (n / l),
$$

where $n$ is the distance normal to the slope and $l$ is a length scale related to the slope angle, static stability, and the assumed-constant diffusivities. This solution indicates an upslope-flowing layer close to the surface changing with distance from the slope to a downslope flow of decreased strength.

Since real upslope flows are invariably turbulent, Prantdl's solution provides at best only a qualitative description of actual upslope flows. Improvements to Prandtl's model have involved using more sophisticated models to represent the turbulent diffusivities, as reviewed by Egger (1990). The most complete treatment to date of Prandtl's problem is that of Schumann (1990), 

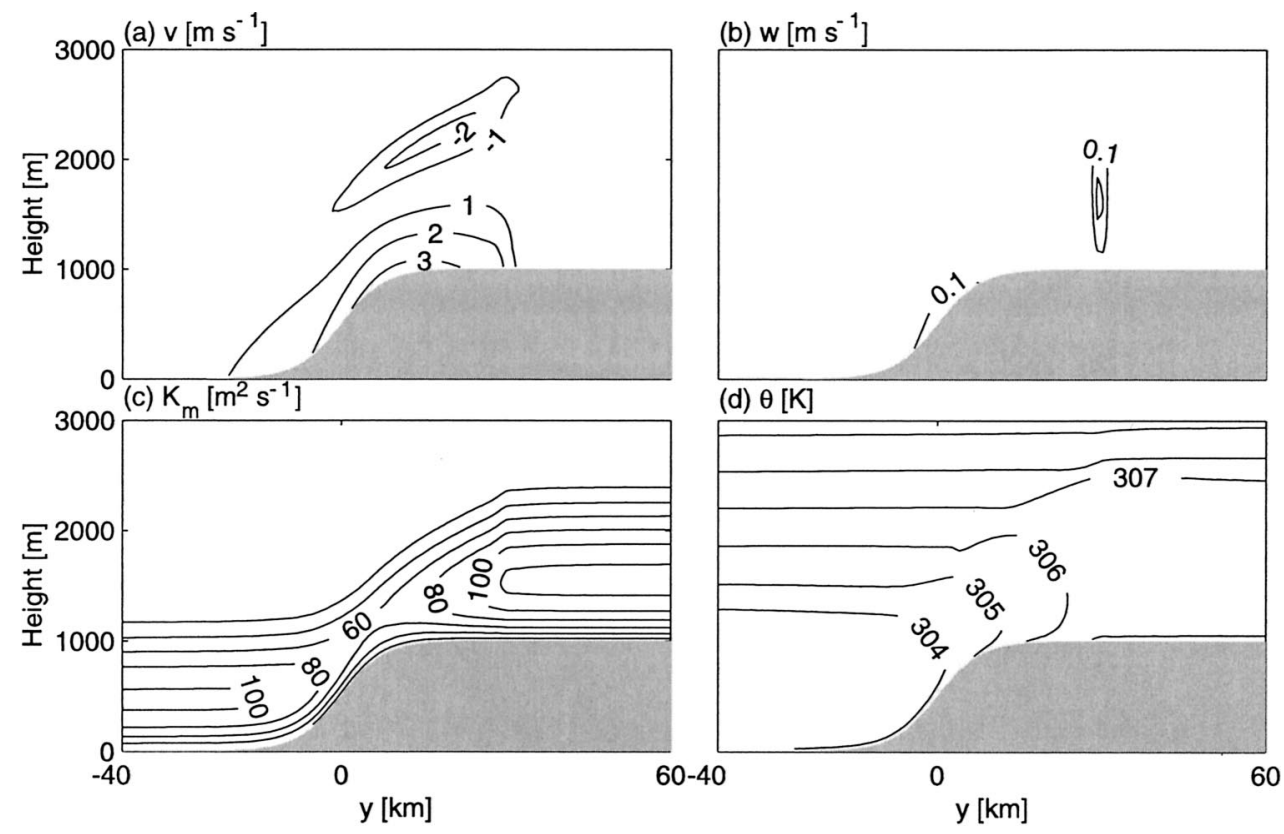

FIG. 4. Solution at $t=6 \mathrm{~h}$ in the case of a two-dimensional plateau for the (a) along-slope wind component, (b) vertical wind component, (c) eddy diffusivity, and (d) potential temperature.

who used a large eddy simulation (LES) model to simulate turbulent heat transfer over an infinitely long slope and found that for small slope angles $\left(\leq 10^{\circ}\right)$ a wellmixed layer is formed, which causes a strong temperature inversion and a strong downslope flow at the outer edge of the unstable boundary layer.

A further significant complication to Prandtl's model is that real slopes are of finite horizontal extent. The infinitely long and constant slope of Prandtl's problem permits the simple rotation of coordinates that allows Prandtl's analytical solutions and makes feasible Schumann's (1990) LES calculation. Further progress toward understanding the factors affecting real slope flows has depended on analytical (Egger 1987a,b) and numerical simulations of flows over finite-extent slopes such as represented by (2), but using a parameterization for the turbulent transfers since LES over such large domains is not viable (e.g., McNider and Pielke 1981; Segal et al. 1987). Such is the approach adopted here.

Figure 4 illustrates the flow produced at $t=6 \mathrm{~h}$ by imposing the heat flux described by (12) along the topography represented by (2). The structure of the upslope flow is similar to the classical infinite-slope solutions described above with a maximum upslope velocity near the ground and return flow aloft (Fig. 4a). The vertical structure of the slope flow can be characterized as a well-mixed layer of upslope flow topped by a return flow stronger than expected from Prandtl's solution, consistent with Schumann's (1990) LES calculation. However, as can be seen in Fig. 4, the most important departure from the Prandtl model is the presence of the plateaus. Far from the slope region, wellmixed layers grow (Fig. 4d) since there is no balancing tendency provided by along-slope cold-air advection. Consistent with the latter is the fact that the mixed layer is shallower over the slope (Figs. 4c,d). Further results on solution sensitivity to the initial stability, slope, and heating intensity can be found in Ye et al. (1987) and Kuwagata and Kondo (1989). Incidentally, the local updraft maximum located near $y=20 \mathrm{~km}$ in Fig. $4 \mathrm{~b}$ is a transient feature associated with the leading edge of the cool air that has risen up the slope during the previous $6 \mathrm{~h}$.

\section{b. Thermally driven flow in a valley with a horizontal floor}

With the valley topography (3) there is now the additional effect of two slope flows drawing air from a common central location, producing a compensating subsidence in the valley. This effect is illustrated in Fig. 5 , where the solutions are shown at $t=6 \mathrm{~h}$, produced as in the previous case with the heat flux (12) but now applied along the valley topography (3). Figure 5 shows that the flow is upslope along the valley sidewalls; there is compensating subsidence in the core of the valley, with a vertical velocity of $0\left(-0.1 \mathrm{~m} \mathrm{~s}^{-1}\right)$. Notice that the subsidence region extends well above the height of the sidewalls (Fig. 5b). The thermal structure inside the valley displays a mostly stable core region, with two layers near the sidewalls where the slope flow has developed. This behavior is in agreement with previous experimental and numerical studies (Bader and McKee 1983, 1985; Rampanelli and Zardi 2004). Figure 5d shows that in the valley a well-mixed layer can be identified only in its lower part. In fact, comparing the field 

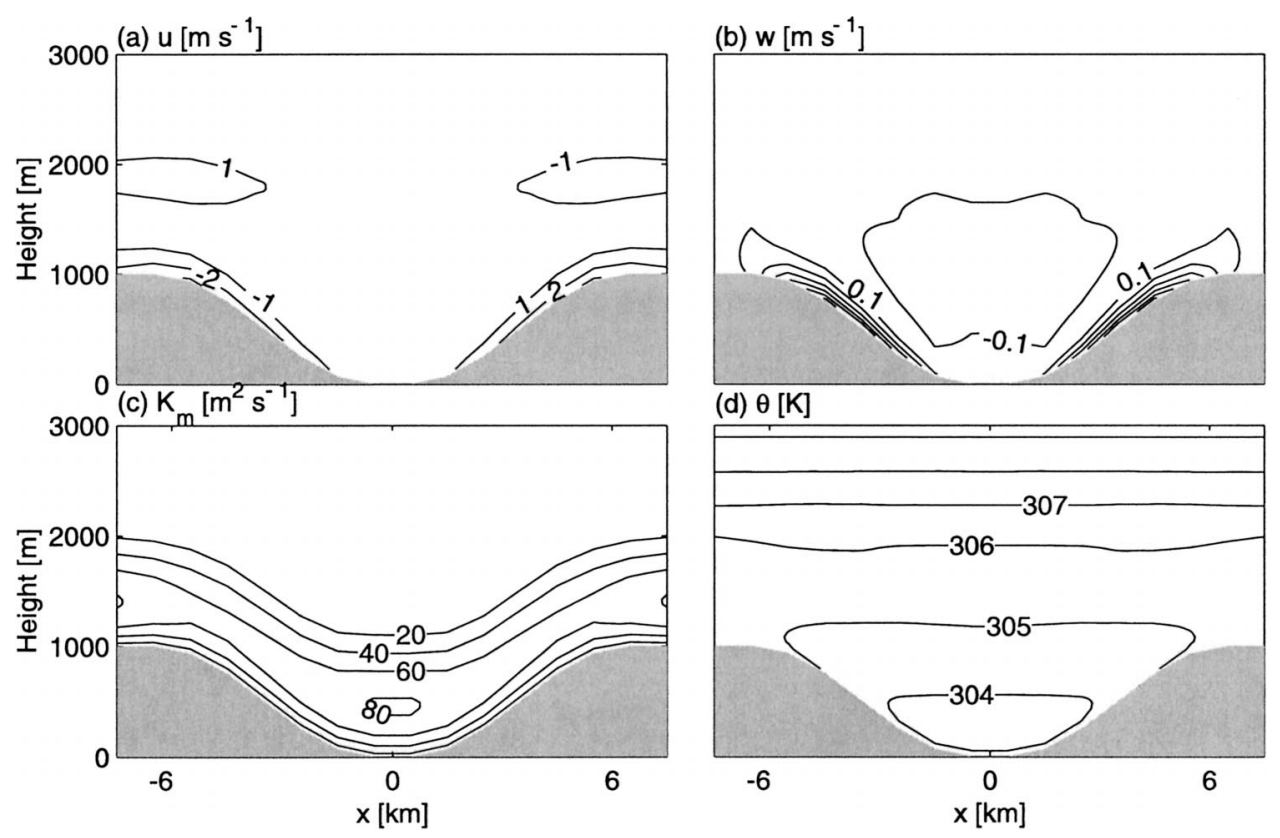

FIG. 5. As in Fig. 4 except for a two-dimensional valley.

of $K_{m}(x, z)$ (Fig. 5c) with that of $\theta(x, z)$ (Fig. 5d) shows that $\theta$ has been modified below $z \approx 2000 \mathrm{~m}$ for all $x$, even though the layer in which $K_{m} \neq 0$ in the valley center only extends to $z \approx 1400 \mathrm{~m}$. This comparison suggests that the advective heat transport plays a crucial role in producing the observed thermal structure, especially in the core region of the valley (Kondo et al. 1989; Noppel and Fiedler 2002). This advective heat transport will be further investigated in section $5 \mathrm{c}$. At this display time of $6 \mathrm{~h}$ two transient updraft features, analogous to that seen in Fig. 4b, have propagated out of the domain and hence are not evident in Fig. 5b.

\section{Thermally driven wind in a valley-plain system}

In this section we describe the numerical solution with heating (12) applied along the full valley-plain topography $h(x, y)$ shown in Fig. 2. By design $h(x, y)$ is the product of the slope connecting two plateaus $h_{Y}(y)$ and the two-dimensional valley $h_{X}(x)$ for which the twodimensional solutions were discussed in the previous section. As a consequence the three-dimensional solutions can be mostly understood as a composite of the two-dimensional plateau and valley solutions (Figs. 45) individually considered. However, as we shall demonstrate below, the valley wind is a uniquely three-dimensional feature of the solution in the valley-plain case.

Figures 6-8 show the solution at $t=6 \mathrm{~h}$ in crossvalley planes located at three along-valley positions. Starting from the valley end (Fig. 6), one observes that the wind field is nearly identical to the two-dimensional valley simulation (Fig. 5). Moving closer to the valley mouth at $y=20 \mathrm{~km}$, Fig. 7 shows that, while the crossvalley circulation is similar to that at the valley end, there is now an up-valley flow for all $x$, and for $z$ approximately less than $1 \mathrm{~km}$; there is down-valley flow at higher altitudes. The along-valley wind speed is highest near the ground and shows a clear negative minimum in the region of the valley mouth (Fig. 8b). The subsidence region in the valley core occurs throughout the valley atmosphere, from the mouth to the end, and the subsequent downward heat transfer produces a stable boundary layer throughout the entire valley core, as in the two-dimensional case (Fig. 5). This effect is evident when comparing panels (e) and (f) of Figs. 6-8, showing that the upward turbulent heat transfer from the ground is limited to the lower part of the boundary layer and that in the upper part, where the subsidence effect is stronger, a different mechanism is at work, as discussed in relation to Fig. 5 .

Figures 9-10 show the solution at $t=6 \mathrm{~h}$ in alongvalley planes located on the side of the domain located at $x=-7.5 \mathrm{~km}$ and at the valley center $(x=0)$, respectively. The solution at the side of the domain (Fig. 9) is very similar to the two-dimensional solution for the plateau (Fig. 4) except that, owing to the valley circulation, there is outflow (inflow) at low (upper) levels over the upper plateau (Fig. 9a). The solution along the valley center (Fig. 10) is unlike either of the twodimensional solutions shown in Figs. 4-5. Figures 10b and $10 \mathrm{~d}$ show the up-valley wind reaching $2 \mathrm{~m} \mathrm{~s}^{-1}$ at the ground at low levels with a slightly stronger return flow aloft. The subsidence shown in Fig. 10c begins near the valley mouth $(y=0)$ and is clearly associated with divergence in the cross-valley plane (Figs. 6-8). 

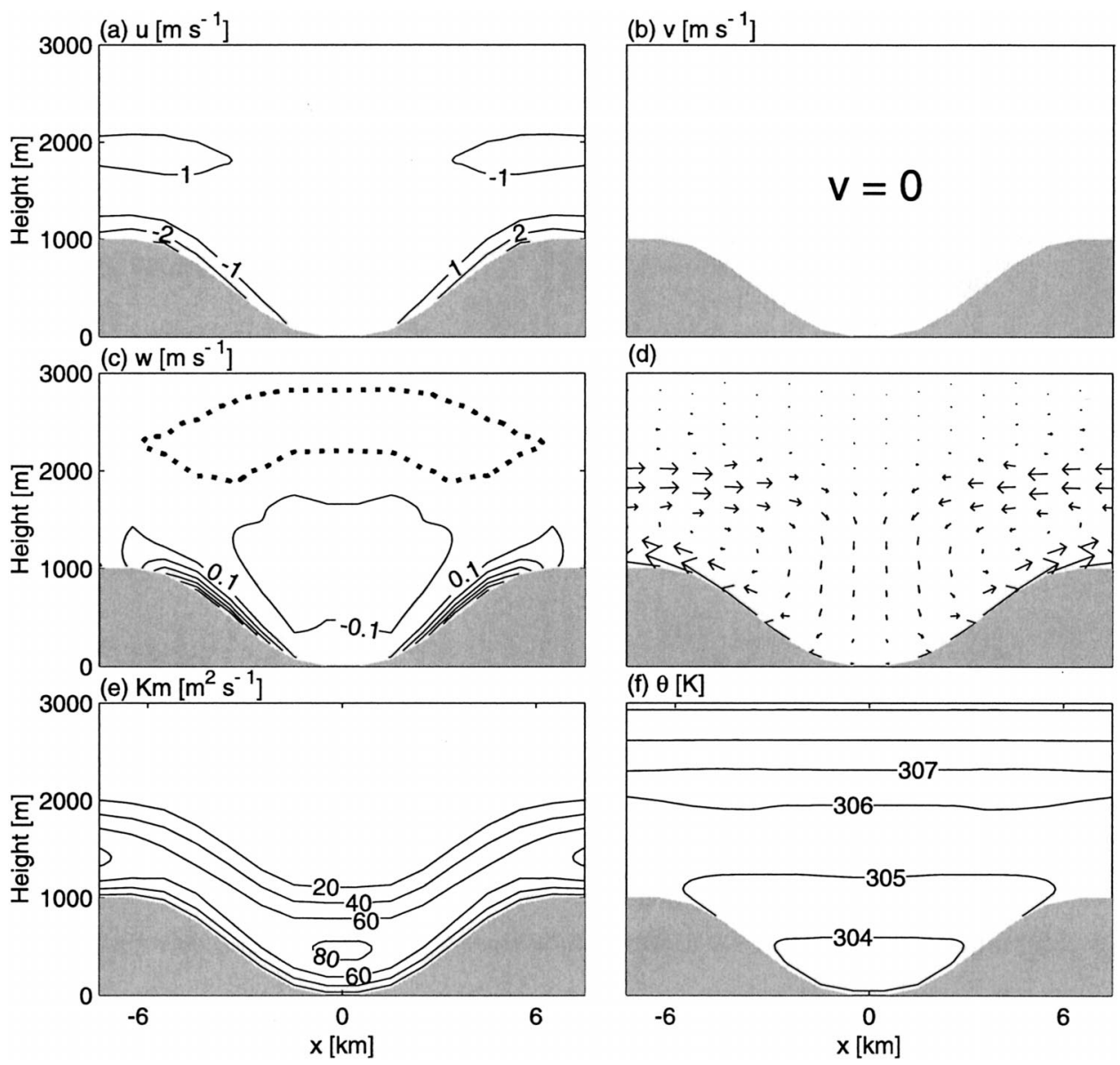

Fig. 6. Cross-valley sections at $y=120 \mathrm{~km}$ (valley end) at $t=6 \mathrm{~h}$ in the case of the three-dimensional plain-valley topography of the (a) cross-valley wind component; (b) along-valley wind component; (c) vertical wind component, the region with $w \geq+0.005 \mathrm{~m} \mathrm{~s}^{-1}$ is indicated with a dotted line; (d) wind vectors; (e) eddy diffusivity; and (f) potential temperature.

This subsidence affects the thermal structure of the boundary layer, as may be seen by comparing Figs. 9f and 10f: The boundary layer in Fig. 9f is mainly coincident with the layer in Fig. 9e where $K_{m} \neq 0$; the boundary layer in Fig. 10f also coincides with the layer where $K_{m} \neq 0$ over the plain; however, in the valley it is strongly influenced by the subsidence effect. This significant potential temperature anomaly above the valley-top level $(z=1 \mathrm{~km})$ means that any attempt to calculate the mean temperature of air within the valley volume by simple estimates (such as the topographical amplification factor, discussed in section 1) must come to terms with the possibility of a significant heat flux through the top of the valley volume.

\section{Explanation of the valley wind}

\section{a. Acceleration of the wind along the valley}

Because the valley floor along the valley center is horizontal, the only effect that could produce an alongvalley wind there from a state of rest is the along-valley pressure gradient $\partial \pi / \partial y$ at $x=0$. Assuming hydrostatic balance in (8), using the last relation of (10), integrating in $z$, and then differentiating the result in $y$ leads to

$$
\left.\frac{\partial \pi}{\partial y} \approx \frac{\partial \pi}{\partial y}\right|_{z=H}+\frac{g}{c_{p}} \int_{z}^{H} \frac{\partial}{\partial y} \frac{1}{\theta} d z^{\prime} .
$$

Analysis of the results indicates that the horizontal pressure gradient at $z=H$ is negligible; therefore neglecting the first term on the rhs of (14) we can estimate the pressure gradient term in (7) as

$$
-c_{p} \Theta \frac{\partial \pi}{\partial y} \approx g \Theta \int_{z}^{H} \frac{1}{\theta^{2}} \frac{\partial \theta}{\partial y} d z^{\prime} .
$$

The solid line in Fig. 11 shows the term on the lhs of (15) as a function of $y$ evaluated at $x=z=0$; it is positive and reaches a maximum near the valley mouth. This structure is consistent with that of the up-valley wind seen along $z=0$ in Fig. 10b. The dots in Fig. 11 show the term on the rhs of (15); the near overlap of the dots with the solid curve in Fig. 11 confirms that the flow occurs under hydrostatic balance and shows 

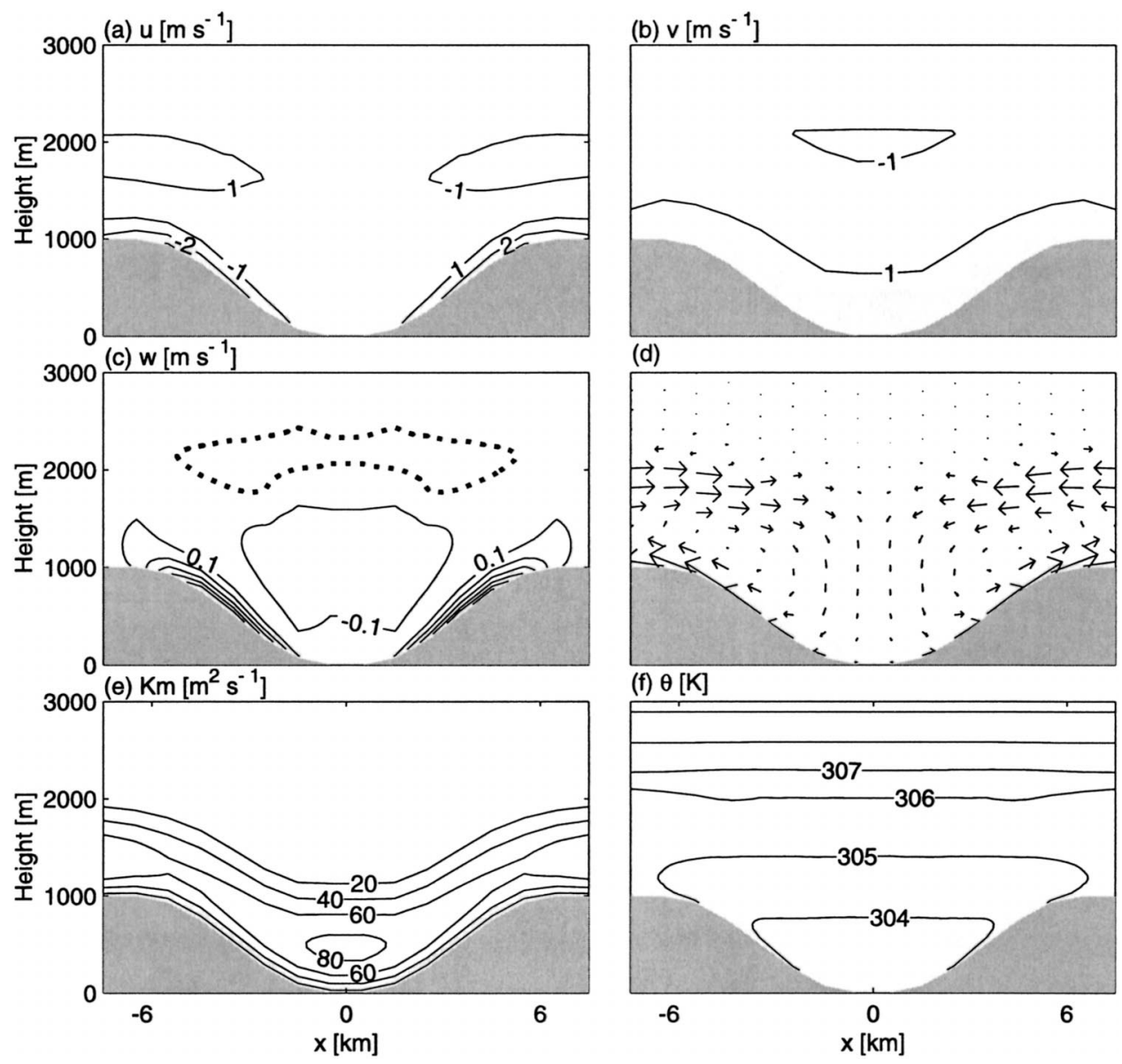

FIG. 7. As in Fig. 6 except for $y=20 \mathrm{~km}$.

the central importance of understanding the vertical structure of the along-valley potential temperature distribution in explaining the valley wind.

Also included in Fig. 11 are the pressure gradient term and its hydrostatic evaluation at $x=0$ and $z=$ $1200 \mathrm{~m}$. The reversal of the sign of the pressure gradient at this upper level is consistent with the occurrence there of the down-valley wind. This reversal displays a qualitative similarity with that found in the above-discussed studies of Prandtl (1942) and Schumann (1990), even in the absence of any upsloping valley floor. However the physical mechanisms producing these apparently similar features are quite different. The mechanism for the elevated layer of downslope flow in Prandtl's (1942) laminar solution (and its extension to the turbulent case) is straightforward: the viscous (turbulent) stress exerted by the thermally driven upslope flow on the layer above it induces adiabatic cooling there; cooling through diffusion of yet higher layers must eventually be balanced at steady state by downslope-flow adiabatic warming. In the present case there is zero ground slope along the valley axis and, as shown with (15), all along-valley motions must be driven by the vertical integral of $\partial \theta / \partial y$. Figure $10 \mathrm{f}$ indicates that, for $z>1800 \mathrm{~m}, \partial \theta / \partial y<0$, which, as shown by (15) and Fig. 11, contributes to a down-valley pressure gradient acceleration at upper levels. Through an analysis of the heat budget below, we demonstrate that the temperature distribution shown in Fig. 10f, which drives both the up- and down-valley winds, is a unique feature of the three-dimensional valley-plain circulation.

\section{b. Comparison with observations}

Figure 12 shows vertical profiles of $\theta$ on the valley axis $(x=0)$ over the plain $(y=-80 \mathrm{~km})$ and within the valley $(y=120 \mathrm{~km})$. As shown in Fig. 12, there are significant differences between the classical vertical profile of potential temperature over plain (cf. Fig. 12 with Fig. 3) and that within the valley. The depth-averaged temperature difference (difference between initial and final) over the plain is roughly $2.0^{\circ} \mathrm{C}$, while that within the valley is roughly $3.3^{\circ} \mathrm{C}$. Table 3 of Vergeiner and Dreiseitl (1987) indicates that the barometric mean temperature difference (in summer) is $2.1^{\circ} \mathrm{C}$ in Munich (the plain) while it is $4.0^{\circ} \mathrm{C}$ at Innsbruck (the valley). Since the measured difference is for the entire heating period $(9 \mathrm{~h})$ and our simulations were carried out only 

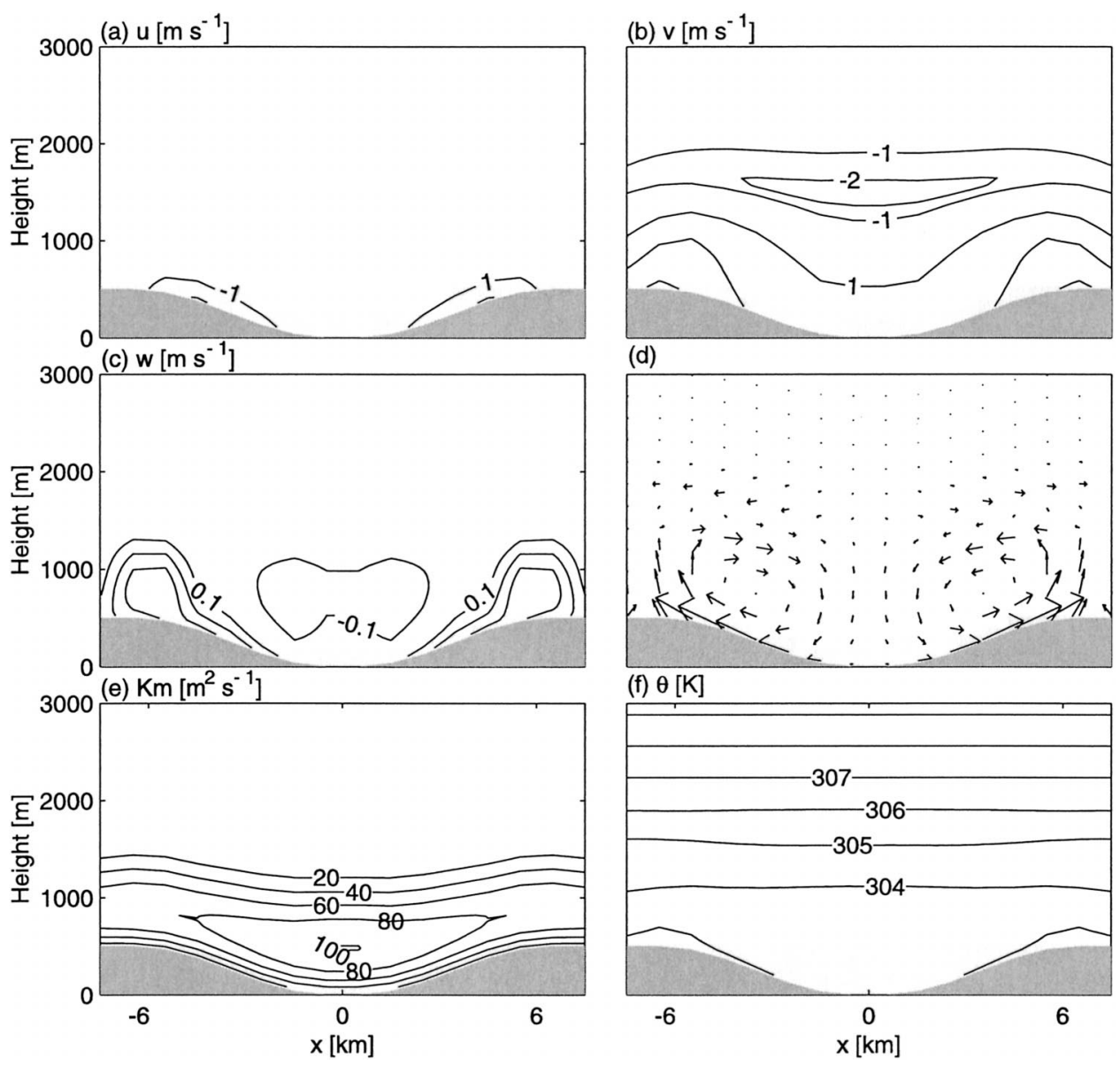

FIG. 8. As in Fig. 6 except for $y=0 \mathrm{~km}$ (valley mouth).

for $6 \mathrm{~h}$, the relative weakness of the simulated excess $\left(3.3^{\circ}-2.0^{\circ} \mathrm{C}\right)$ might be explained. Consistent with this weakness in the simulated temperature excess in the valley is the fact that the simulated maximum up-valley wind is only $2 \mathrm{~m} \mathrm{~s}^{-1}$, while the observations in Fig. 3 of Vergeiner and Dreiseitl (1987) show values closer to $6 \mathrm{~m} \mathrm{~s}^{-1}$. We have carried out our simulations for a period of 9 hours and find that the depth-averaged temperature excess does not increase much after the initial $6 \mathrm{~h}$, and the averaged temperature of the valley atmosphere remains roughly $1.4^{\circ} \mathrm{C}$ warmer than over the plain. In fact the two depth-averaged temperatures' differences reach $3.6^{\circ} \mathrm{C}$ over the plain and $5.0^{\circ} \mathrm{C}$ in the valley. Due to this nearly constant temperature unbalance between valley and plain, the maximum up-valley wind does not increase much after the initial $6 \mathrm{~h}$ of simulation, reaching $2.1 \mathrm{~m} \mathrm{~s}^{-1}$, but the region where the up-valley wind is blowing becomes wider in the along-valley direction.

The obtained values are still on the low side; however, it should be kept in mind that the Inn Valley has a slope roughly 1 in 500. We carried out simulations with a valley slope of 1 in 500 and found in a 6-h simulation that the depth-averaged temperature excess increased to $\left(4.2^{\circ}-2.0^{\circ} \mathrm{C}\right)$ and the maximum up-valley wind in- creases to $2.6 \mathrm{~m} \mathrm{~s}^{-1}$. Hence we believe that the present simulations are at least roughly consistent with the observations.

Finally, contemporaneosly with the present work, analysis of observations in the Riviera Valley (Rotach et al. 2004) is showing that subsidence heating is a major contributor to heating in that valley.

\section{c. Heat budget}

Although it is qualitatively clear form Fig. 10 that subsidence is a strong contributor to the warming of the valley core, a quantitative evaluation of the effect is desirable and is given here. The thermodynamic energy budget within the model atmosphere is given by (9), which can be rewritten as

$$
\begin{aligned}
\frac{\partial \theta}{\partial t}= & -u \frac{\partial \theta}{\partial x}-v \frac{\partial \theta}{\partial y}-w \frac{\partial \theta}{\partial z}+\frac{\partial}{\partial z}\left[K_{m}\left(\frac{\partial \theta}{\partial z}-\gamma\right)\right] \\
& +K_{H} \nabla_{H}^{2} \theta .
\end{aligned}
$$

The terms on the rhs of (16) can be separately evaluated in order to assess the differences between the evolution of the atmosphere over the plain and that within the 

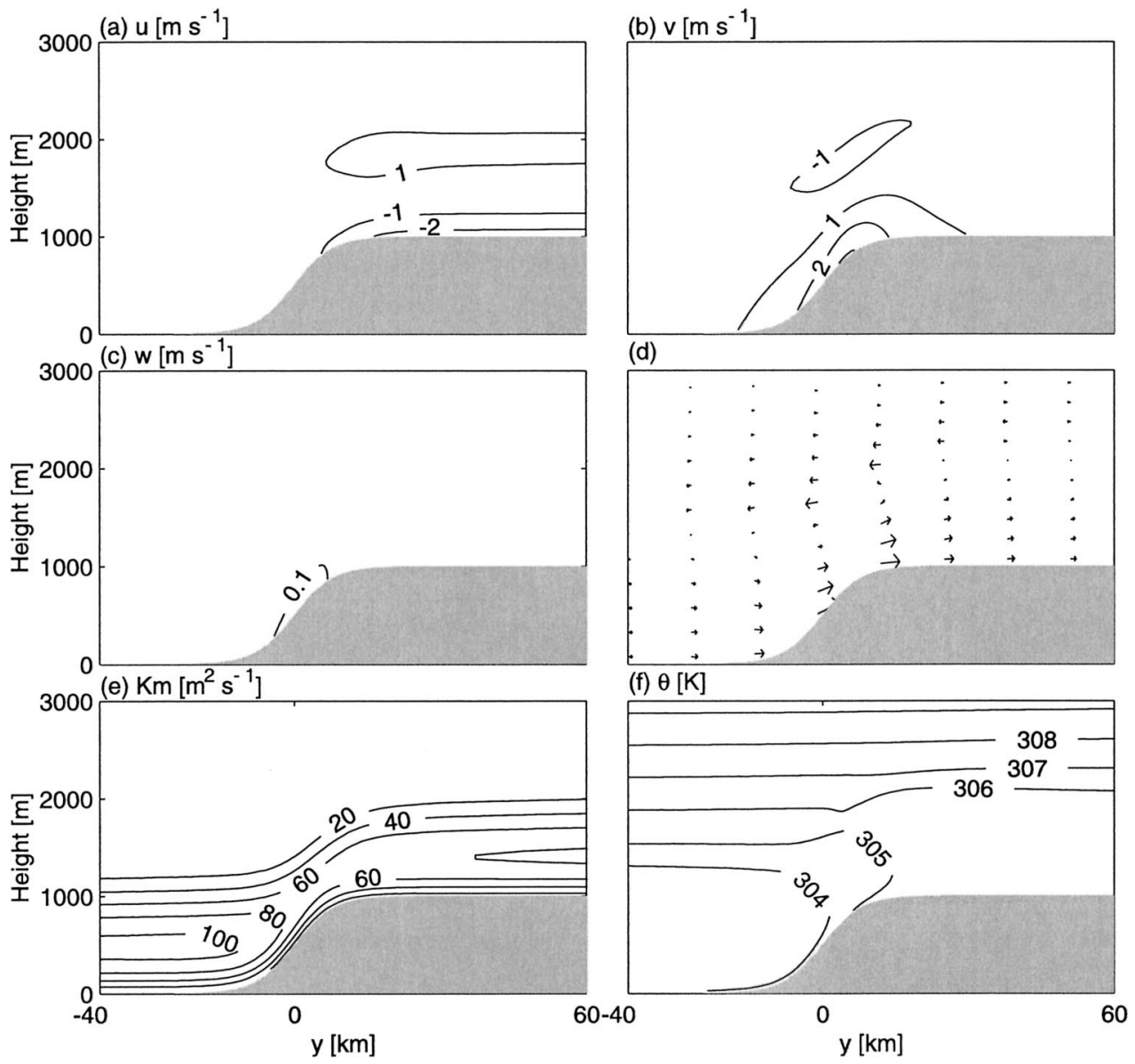

FIG. 9. Along-valley sections at $x=-7.5 \mathrm{~km}$ (left side of valley) at $t=6 \mathrm{~h}$ in the case of the threedimensional plain-valley topography of the (a) cross-valley wind component, (b) along-valley wind component, (c) vertical wind component, (d) wind vectors, (e) eddy diffusivity, and (f) potential temperature.

valley. Figure 13a shows the vertical profiles of the terms providing the major contributions to (16) at $y=$ $-40,0$, and $80 \mathrm{~km}$, along the valley axis $x=0$. Since $u=0$ at $x=0$, only four of the five terms on the rhs of (16) can contribute. In addition, Fig. 13a shows that at all three locations the along-valley temperature advection is small, so only the latter three terms on the rhs side need be considered in the following discussion.

Over the plain $(y=-40 \mathrm{~km})$, Fig. 13a shows that the divergence of the turbulent heat flux $\partial / \partial z\left[K_{m}(\partial \theta / \partial z\right.$ $-\gamma)]$ is the main contributor to the potential temperature tendency and that the remaining terms are negligible. In the valley $(y=0,80 \mathrm{~km})$, Fig. 13a shows that the vertical-advection term is dominant in the upper part of the boundary layer and the turbulent transport is the most important term in the lower part of the layer, where the effect of heating from the ground is stronger. The combined effect of the vertical advection and the vertical turbulent flux of heat produces the modification of the vertical structure of the boundary layer shown in Fig. 12. Hence vertical advection of potentially warmer air downward from the free atmosphere is the most im- portant contributor to warming in the upper layers within and above the valley region.

As discussed at the end of section 5a, at heights above $z \approx 1800 \mathrm{~m}$, Fig. 10f indicates that the valley atmosphere is relatively cool with respect to that of the plain. Here we take a closer look at both this relative cooling and the reasons for it. Figure 12 provides a comparison between vertical profiles of potential temperature taken over the plain $(y=-80 \mathrm{~km})$ with those well within the valley $(y=120 \mathrm{~km})$ at the mature stage of the valley wind $(t=6 \mathrm{~h})$; Fig. 12 shows that the valley becomes cooler than that over the plane above $z \approx 1800 \mathrm{~m}$. This figure, together with the $\theta$ distribution shown in Fig. $10 \mathrm{f}$, implies that $\partial \theta / \partial y$ changes from positive to negative near $z \approx 1800 \mathrm{~m}$. The heat budget at the same location (Fig. 13a) shows that the cool air aloft is due to rising motion there. The rising motion at upper levels in the valley core is induced by the meeting of the return flows of the opposing slope flows occurring on the valley walls (Figs. 6-8). The height of the latter is to a first approximation the height of the boundary layer over the plateaus surrounding the valley. With the establishment 

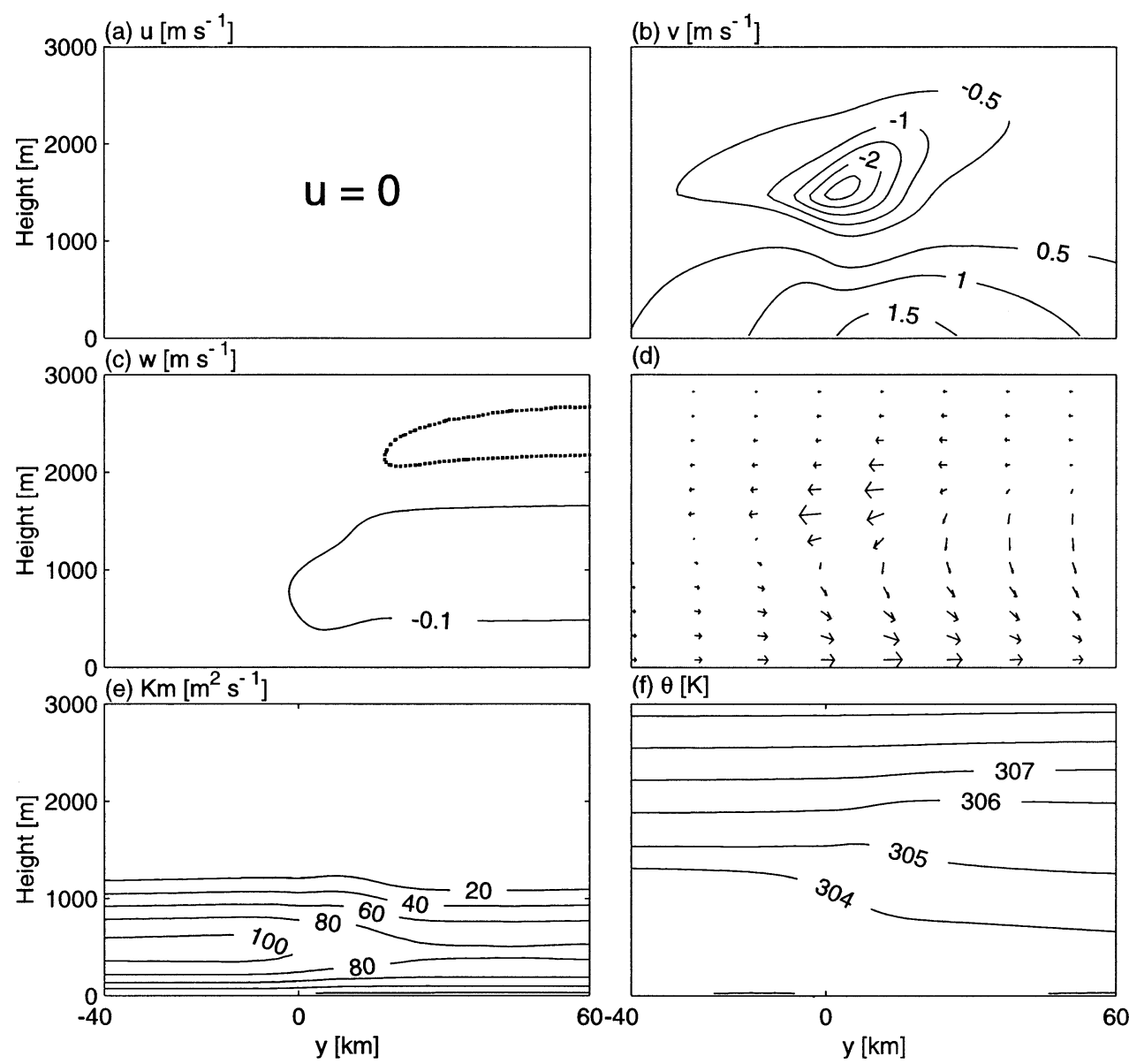

\section{(f) $\theta[\mathrm{K}]$}

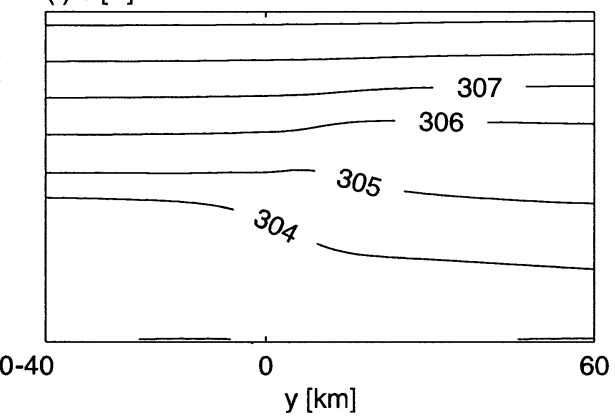

FIG. 10. As in Fig. 9 except for $x=0 \mathrm{~km}$ (valley center).

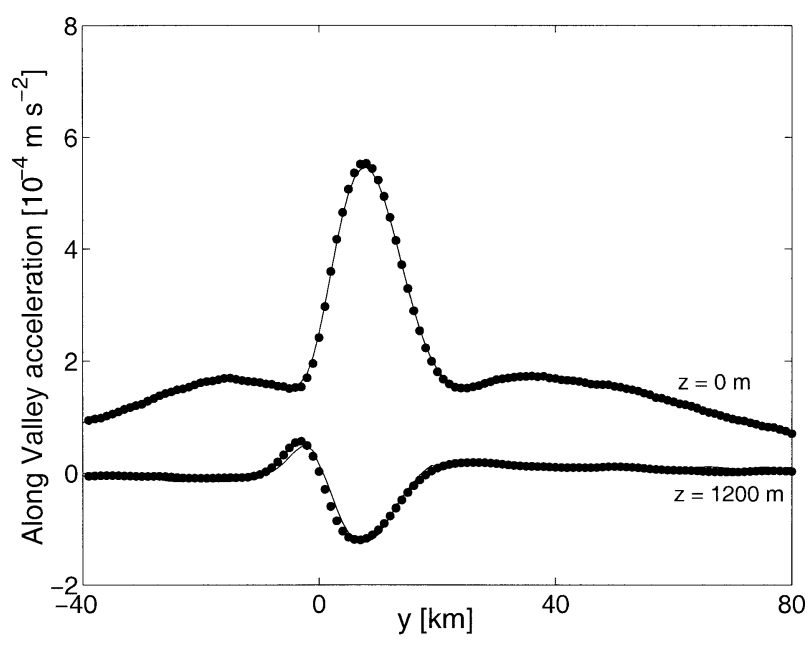

FIG. 11. Along-valley pressure gradient acceleration at the valley center, $-c_{p} \Theta \partial \pi / \partial y$ (solid lines) from the model output along with $g \Theta \int_{z}^{H}\left(1 / \theta^{2}\right) \partial \theta / \partial y d z^{\prime}$, which is the pressure gradient acceleration assuming hydrostatic balance (dots). Upper and lower curves refer to evaluation at $z=0$ and $1200 \mathrm{~m}$, respectively.

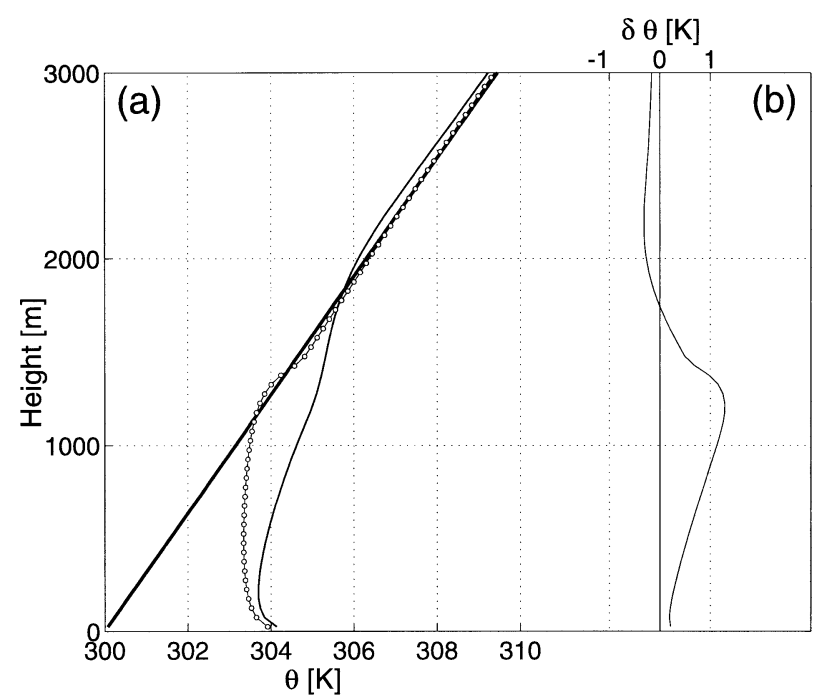

FIG. 12. (a) Vertical profiles of potential temperature along the valley axis $(x=0 \mathrm{~m})$ over the plain $(y=-80 \mathrm{~km}$, solid line $)$ and in the valley region ( $y=120 \mathrm{~km}$; bullet line $)$ at $t=6 \mathrm{~h}$. The dark solid line shows the initial profile. 

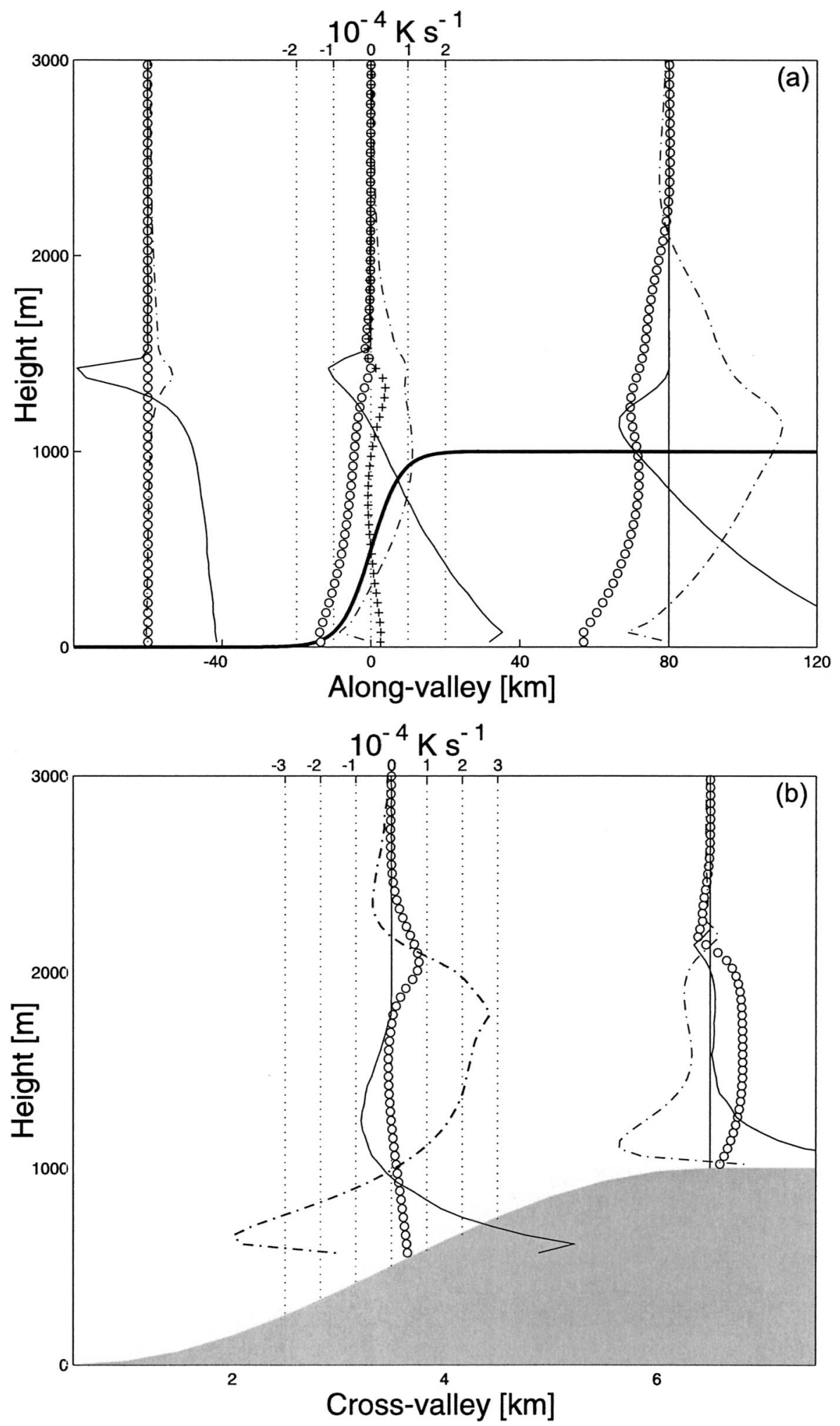

FIG. 13. Vertical profiles of the terms in the energy budget (16) (a) at $y=-60,0,80 \mathrm{~km}$ in the middle of the valley: turbulent heating, $\partial / \partial z\left[K_{m}(\partial \theta / \partial z-\gamma)\right]$ (solid line); vertical advection $w \partial \theta / \partial z$ (dotted line); along-valley advection $v \partial \theta / \partial y$ (diamond line); and the numerical filter $K_{H} \nabla_{H}^{2} \theta$ (bullet line) and (b) at $y=80 \mathrm{~km}$ and $x=3,6 \mathrm{~km}$. Labeling convention is the same as in (a), except advection represents vertical and along-slope contributions. 
of a region of $\partial \theta / \partial y<0$ along the valley axis, we can see through (15) and Fig. 11 the reasons for a downvalley wind at upper levels along the valley center.

It is interesting to note here that the occurrence of such an upper counterflow and the governing physical mechanisms have been the subject of a long and controversial debate between scientists at the early stages of valley wind studies. Wagner (1938, his section 5), commenting on the upper-level down-valley wind, identified as a contributing factor (among others) the existence of potentially cooler air above the relatively warm valley boundary layer; he further speculated that the potential cool air is produced there by upward vertical motion resulting from the convergence of the two opposing return flows associated with the upslope flows on the valley walls. Hence Wagner's (1938) explanation is in substantial agreement with the present findings.

Figure 13a shows that the effect of the numerical filter is to cool the valley center; this cooling is consistent with the fact that the effects described above tend to produce maximum $\theta$ in the valley center [panel (f) of Figs. 6-10]. Hence the effect of the filter is simply to reduce the horizontal gradient of $\theta$ and, through (16), reduce the magnitude of the simulated valley wind, but otherwise does not effect the fundamental interpretation of the valley wind given here.

The heat budgets within the valley at $y=80 \mathrm{~km}$ on the slope and at the valley top are shown in Fig. 13b. The heat budget at $x=3 \mathrm{~km}$ (midslope) indicates a near balance between turbulent heating and along-slope advection, reminiscent of the Prandtl model; the heat budget at $x=6 \mathrm{~km}$ (valley top) also indicates a rough balance between turbulent heating and along-slope advection. In all cases there is a net positive tendency since the heating is still in progress at $6 \mathrm{~h}$.

\section{Conclusions}

In the present work we have reconsidered the basic physical mechanisms governing the daytime evolution of up-valley winds in mountain valleys. Using a series of numerical simulations of thermally driven flow over idealized three-dimensional topography, we have been able to evaluate the mechanisms of excess valley heating, which, through the hydrostatic law, implies an upvalley acceleration of air from an adjacent plain. In particular, our analysis of the numerical solutions shows that the compensating subsidence in the valley center is the most important contributor to this excess heating. This mechanism in which subsidence in the valley produces the valley-plain temperature contrast improves on the current textbook description based on bulk thermodynamics arguments.

The understanding of valley winds developed here has several important implications. For example, the stability of the atmosphere above the valley is expected to be an important factor since it will effect the subsidence heating within the valley. Another implication is that the up-valley wind can occur even in a valley with vertical sidewalls (valley volume $=$ plain volume), since it is to be expected that there would still be compensating subsidence at the valley center in such a valley. The results here suggest that the subsidence effect will produce noticeable differences in the observed vertical structure of the convective boundary layer within and outside of a valley (Rampanelli and Zardi 2004; Rotach et al. 2004).

Since the desire here was to deepen our understanding of the dynamics of the up-valley wind, we have intentionally limited this study to a topography based on parameters that approximately describe typical mountainvalley situations. An important following step would be to carry out a systematic and more comprehensive series of numerical solutions varying the topographical parameters over the range of observed values.

Perhaps the most fundamental limitation of the present study is its reliance on a parameterization to simulate the turbulent convective heat transfer from the ground into the atmosphere. A simulation of the thermally driven flow using the technique of large eddy simulation as in Schumann (1990) would require a grid with much finer horizontal resolution ( $\sim 50 \mathrm{~m})$ and, accordingly, a much smaller time step (1.2 s); such a calculation would be about 8000 times more costly than the three-dimensional computation reported on here. While costly, such calculations are presently possible and should be pursued in order to cover the gap between the smallest mesoscale phenomena, which can be explicitly resolved by numerical weather prediction models, and smallerscale phenomena such as turbulence, which can be explicitly treated only by large eddy simulation models.

Finally we state again that, in order to isolate the mechanisms of up-valley winds in their purest form, a number of practically important effects have been neglected, such as the occurrence of an initial stably stratified layer capped by a ground-based inversion (cf. Whiteman 1982; Whiteman and McKee 1982; Bader et al. 1987), surface stress, an upward-sloping valley floor, the Coriolis effect, nonuniform insolation depending on the orientation of the valley axis with respect to sun angle (Whiteman et al. 1989a,b) as well as on shading by surrounding mountains' shape (Colette et al. 2003). The relative importance of those effects to the one studied here needs to be determined in future work.

Acknowledgments. This work has been partly supported by the Provincia Autonoma di Trento under the project PAT-UNITN 2001 and by granting a leave of absence to G. Rampanelli for completing his Ph.D. program. We acknowledge the Mesoscale and Microscale Meteorology Division for its support of a visit by D. Zardi to NCAR, and the Department of Civil and Environmental Engineering for its support of a visit by R. Rotunno to the University of Trento, which made this work possible. 


\section{REFERENCES}

Bader, D. C., and T. B. McKee, 1983: Dynamical model simulations of the morning boundary layer development in deep mountain valleys. J. Climate Appl. Meteor., 22, 341-351.

$\longrightarrow$, and -1985 : Effects of shear, stability and valley characteristics on the destruction of temperature inversions. J. Climate Appl. Meteor., 24, 805-815.

$\longrightarrow,-$, and G. J. Tripoli, 1987: Mesoscale boundary layer evolution over complex terrain. Part I: Numerical simulation of the diurnal cycle. J. Atmos. Sci., 44, 2823-2837.

Colette, A., F. Katopodes, and R. L. Street, 2003: A numerical study of inversion-layer breakup and the effects of topographic shading in idealized valleys. J. Appl. Meteor., 42, 1255-1272.

Defant, F., 1949: Zur theorie der Hangwinde, nebst Bemerkungen zur Theorie der Berg- und Talwinde. Arch. Meteor. Geophys. Bioklim., A1, 421-450. [English translation: Whiteman, C. D., and E. Dreiseitl, 1984: Alpine Meteorology: Translations of Classic Contributions by A. Wagner, E. Ekhart and F. Defant. PNL5141/ASCOT-84-3, Pacific Northwest Laboratory, 95-121.]

- 1951: Local winds. Compendium of Meteorology, T. M. Malone, Ed., Amer. Meteor. Soc., 655-672.

Egger, J., 1987a: Simple models of the valley-plain circulation. Part I: Minimum resolution model. Meteor. Atmos. Phys., 36, 231242.

_ $1987 \mathrm{~b}$ : Simple models of the valley-plain circulation. Part II: Flow resolving model. Meteor. Atmos. Phys., 36, 243-254.

_ 1990: Thermally forced flows theory. Atmospheric Processes over Complex Terrain, Meteor. Monogr., No. 45, Amer. Meteor. Soc., 43-57.

Kondo, J., T. Kuwagata, and S. Haginoya, 1989: Heat budget analysis of nocturnal cooling and daytime heating in a basin. J. Atmos. Sci., 46, 2917-2933.

Kuwagata, T., and J. Kondo, 1989: Observation and modeling of thermally induced up-slope flow. Bound.-Layer Meteor., 49, 265-293.

Li, J. G., and B. W. Atkinson, 1999: Transition regimes in valley airflows. Bound.-Layer Meteor., 91, 385-411.

McNider, R. T., and R. A. Pielke, 1981: Diurnal boundary layer development over sloping terrain. J. Atmos. Sci., 38, 2198-2212.

Michalakes, J., S. Chen, J. Dudhia, L. Hart, J. Klemp, J. Middlecoff, and W. Skamarock, 2000: Development of a next-generation regional weather research and forecast model. Proc. Ninth ECMWF Workshop on the Use of Parallel Processors in Meteorology, ANL/MCS-P868-0101, Reading, United Kingdom, Argonne National Laboratory, 105-107.

Neininger, B., 1982: Mesoklimatische Messungen im Oberwallis (Mesoclimatic measurements in the Upper Valais). Ann. Meteor. 19, $105-107$

Nickus, U., and I. Vergeiner, 1984: The thermal structure of the Inn Valley atmosphere. Arch. Meteor. Geophys. Bioklim., A33, 199_ 215.

Noppel, H., and F. Fiedler, 2002: Mesoscale heat transport over complex terrain by slope winds-A conceptual model and numerical simulations. Bound.-Layer Meteor., 104, 73-97.

Prandtl, L., 1942: Führer durch die Strömungslehre. Braunschweigh Vieweg und Sohn, 407 pp. [English translation: Prandtl, L., 1952: Essentials of Fluid Dynamics. Hafner, 452 pp.]

Rampanelli, G., and D. Zardi, 2004: A method to determine the cap- ping inversion of the convective boundary layer. J. Appl. Meteor., 43, 925-933.

Rotach, M. W., M. Andretta, P. Calanca, A. P. Weigel, and R. Vogt, 2004: On the turbulence structure over highly terrain: Key findings from the MAP-Riviera Project. Extended Abstracts, 11th Conf. on Mountain Meteorology, Mt. Washington Valley, NH, Amer. Meteor. Soc., CD-ROM, 6.1.

Schumann, U., 1990: Large-eddy simulation of the up-slope boundary layer. Quart. J. Roy. Meteor. Soc., 116, 637-670.

Segal, M., Y. Ookuchi, and R. A. Pielke, 1987: On the effect of steep slope orientation on the intensity of daytime upslope flow. $J$. Atmos. Sci., 44, 3587-3592.

Steinacker, R., 1984: Area-height distribution of a valley and its relation to the valley wind. Beitr. Phys. Atmos., 57, 64-71.

Stull, R. B., 1988: An Introduction to Boundary Layer Meteorology. Kluwer Academic, $670 \mathrm{pp}$

Troen, I., and L. Mahrt, 1986: A simple model of the atmospheric boundary layer: Sensitivity to surface evaporation. Bound.-Layer Meteor., 37, 129-148.

Vergeiner, I., 1982: Eine energetische theorie der hangwinde (An energetic theory of slope winds). Proc. Int. Tagung Alpine Meteorologie, Tagungsbericht, Berchtesgaden, Germany, 102-105.

_ servations and elementary thoughts. Meteor. Atmos. Phys., 36, 264-286.

Wagner, A., 1932: Der taegliche Luftdruck- und Temperaturgang in der freien Atmosphaere und in Gebirgstaelern (The daytime air pressure and temperature variation in the free atmosphere and in mountain valleys). Gerl. Beitr. Geophys., 37, 315-344.

—_ 1938: Theorie und Beobachtung der periodischen Gebirgswinde (Theory and observation of periodic mountain winds). Gerl. Beitr. Geophys., 52, 408-449. [English translation: Whiteman, C. D., and E. Dreiseitl, 1984: Alpine Meteorology: Translations of Classic Contributions by A. Wagner, E. Ekhart and F. Defant, PNL-5141/ASCOT-84-3, Pacific Northwest Laboratory, 11-43.]

Whiteman, C. D., 1982: Breakup of temperature inversion in Colorado mountain valleys. Part I: Observations. J. Appl. Meteor., 21, 270-289.

_ 1990: Observations of thermally developed wind systems in mountainous terrain. Atmospheric Processes over Complex Terrain, Meteor. Monogr., No. 45, Amer. Meteor. Soc., 5-42.

- and T. B. McKee, 1982: Breakup of temperature inversion in Colorado mountain valleys. Part II: Thermodynamic model. $J$. Appl. Meteor., 21, 290-302.

- , K. J. Allwine, L. J. Fritschen, M. M. Orgill, and J. R. Simpson, 1989a: Deep valley radiation and surface energy budget microclimates. Part I: Radiation. J. Appl. Meteor., 28, 414-426.

$\ldots,-, \ldots, \ldots$, and $-1989 \mathrm{~b}$ : Deep valley radiation and surface energy budget microclimates. Part II: Energy budget. $J$. Appl. Meteor., 28, 427-437.

Wicker, L. J., and W. C. Skamarock, 2002: Time-splitting methods for elastic models using forward time schemes. Mon. Wea. Rev., 130, 2088-2097.

Ye, Z. J., M. Segal, and R. A. Pielke, 1987: Effects of atmospheric thermal stability and slope steepness on the development of daytime thermally induced upslope flow. J. Atmos. Sci., 44, 33413354. 